\title{
Yếu tố ảnh hưởng đến việc áp dụng VietGAP của hộ trồng xoài ở Đồng bằng sông Cửu Long
}

\section{Factors influencing mango farmers' adoption of VietGAP standards in the Mekong Delta}

\author{
Trần Quốc Nhân ${ }^{1 *}$, Lương Hoàng Phúc ${ }^{1}$, Nguyễn Văn Nay ${ }^{1}$, Lê Văn Dễ ${ }^{1}$ \\ ${ }^{1}$ Trường Đại học Cần Thơ, Việt Nam \\ *Tác giả liên hệ, Email: tqnhan@ ctu.edu.vn
}

\section{THÔNG TIN}

DOI:10.46223/HCMCOUJS.

Ngày nhận: 27/02/2021

Ngày nhận lại: 10/04/2021

Duyệt đăng: 08/05/2021

Tù khóa:

chấp nhận; Đồng bằng sông Cưu Long; VietGAP; yếu tố

Keywords:

adoption; Mekong Delta; VietGAP; factor

\section{TÓM TẮT}

Nghiên cứu nhằm xác định các yếu tố ảnh hưởng đến việc chấp nhận áp dụng tiêu chuẩn VietGAP vào sản xuất xoài của nông hộ ở Đồng Bằng Sông Cửu Long (ĐBSCL). Số liệu sử dụng cho nghiên cứu được thu thập từ 110 hộ sản xuất xoài, trong đó 49 hộ sản xuất theo quy chuẩn VietGAP và 61 hộ sản xuất tự do tại tỉnh Hậu Giang và Sóc Trăng. Mô hình hồi qui nhị phân (logit) được sử dụng chủ yếu trong nghiên cứu để phân tích số liệu. Kết quả nghiên cứu cho thấy nếu nông hộ có tham gia vào các tổ chức nông dân, tần suất tiếp cận Cán Bộ Khuyến Nông $(\mathrm{CBKN})$ nhiều và hộ có có tiếp cận với Internet sẽ có xu hướng chấp nhận áp dụng quy chuẩn VietGAP vào sản xuất xoài. Trong khi đó, trình độ học vấn chủ hộ càng cao thì hộ ít có xu hướng áp dụng VietGAP.

ABSTRACT
This study aimed to examine factors influencing mango
farmers' adoption of VietGAP standards in the Mekong Delta,
Vietnam. Data used for this study were gathered from 110 mango
growers, consisting of 49 VietGAP adopters and 61 VietGAP non-
adopters in Hau Giang and Soc Trang provinces. The logit model
was pricipally employed to analyze the data. The findings showed
that a household participating in farmers' organizarion, acontacting
frequence of farmer with extension worker and accessing to
Internet is more likely to adopt VietGAP standards in mango
production. Yet household's head with higher level of education is
unlikely to apply VietGAP standards.

\section{Giới thiệu}

Trong những năm gần đây, kim ngạch xuất khẩu ngành hàng rau quả của Việt Nam đạt giá trị tương đối cao trong nhóm ngành nông, lâm và thủy sản. Kim ngạch xuất khẩu rau quả năm 2019 đạt 3.8 tỷ USD, trong đó Trung Quốc vẫn là thị trường xuất khẩu rau quả lớn nhất của nước ta với tỷ trọng khoảng 65\% (Bộ Công thương, 2020). Thời gian gần đây, kim ngạch xuất khẩu rau quả sang thị trường Trung Quốc có xu hướng giảm do sự tăng cường kiểm soát chặt nhập khẩu các mặt hàng rau quả từ Việt Nam thông qua các biện pháp kiểm dịch, kiểm nghiệm, kiểm tra chất 
lượng và truy xuất nguồn gốc.

Trước yêu cầu ngày càng khắt khe của các nước nhập nhập khẩu trái cây về an toàn thực phẩm, nông dân cần thay đổi phương thức sản xuất theo hướng an toàn nhằm góp phần duy trì xuất khẩu cũng như tính bền vững cho ngành cây ăn trái. Dù là vùng sản xuất cây ăn trái trọng điểm của cả nước, tuy nhiên theo số liệu thống kê chưa đầy đủ, diện tích vườn cây ăn trái sản xuất theo quy trình thực hành nông nghiệp tốt (GAP) ở ĐBSCL còn rất hạn chế. Diện tích đạt chứng nhận GAP chỉ chiếm khoảng $1 \%$ tổng diện tích cây ăn trái của toàn vùng. Các mô hình sản xuất theo tiêu chuẩn GAP lại thiếu tính bền vững, nhiều mô hình thực nghiệm sản xuất thành công ở quy mô nhỏ nhưng khi nhân rộng thì thất bại vì đa số nông dân chưa muốn sản xuất theo quy trình GAP (Thai Nguyen, 2015). Nghiên cứu của N. Q. Tran, Nguyen, và Nguyen (2016) cho thấy không ít nông dân sau khi đạt chứng nhận GAP thì quay lại sản xuất theo truyền thống.

Nhằm cải thiện vấn đề an toàn sản phẩm nông nghiệp và niềm tin đối với người tiêu dùng, năm 2008, Bộ Nông nghiệp và Phát triển Nông thôn (2008) đã ban hành Quyết định số 379/QĐBNN-KHCN về quy trình thực hành sản xuất nông nghiệp tốt cho rau, quả tươi an toàn tại Việt Nam (VietGAP). Đến năm 2017, Bộ Khoa học và Công nghệ ban hành tiêu chuẩn Thực hành nông nghiệp tốt tại Việt Nam áp dụng trong lĩnh vực trồng trọt - TCVN 11892-1:2017 (Bộ Nông nghiệp và Phát triển Nông thôn, 2008). Trong thực tế sản xuất, việc áp dụng tiêu chuẩn VietGAP vào sản xuất đã mang lại hiệu quả cao cho người dân. Nhiều nghiên cứu cho thấy, việc áp dụng tiêu chuẩn VietGAP vào sản xuất đã giúp nông dân đạt lợi nhuận cao hơn so với hộ không áp dụng (Bui et al., 2020; Duong \& Nguyen, 2014; Nguyen, Le, Tran, \& Vo, 2013; H. M. Tran, Le, \& Dang, 2020; Pham, Pham, \& Nguyen, 2020; Vo, 2014).

Một số nghiên cứu về các yếu tố có ảnh hưởng đến việc chấp nhận áp dụng VietGAP cũng được thực hiện trong thời gian gần đây. Nghiên cứu của Bui và cộng sự (2020) phân tích các yếu tố ảnh hưởng đến khả năng áp dụng mô hình VietGAP của hộ trồng chè ở tỉnh Lâm Đồng. Ho, Nanseki, và Chomei (2017) cũng nghiên cứu các yếu tố ảnh hưởng đến quyết định áp dụng VietGAP của hộ trồng chè ở Thái Nguyên. Le, Pabuayon, Catelo, và Sumalde (2016) tập trung đánh giá các yếu tố ảnh hưởng đến việc chấp nhận áp dụng VietGAP vào sản xuất của hộ trồng vải thiều ở tỉnh Bắc Giang. Trong khi đó, ĐBSCL là vùng chuyên canh cây ăn trái lớn của cả nước lại chưa có những nghiên cứu về yếu tố ảnh hưởng đến việc chấp nhận áp dụng VietGAP vào sản xuất cây ăn trái, đặc biệt là hộ trồng xoài.

Xoài được xem là một trong những cây trồng chủ lực trong nhóm cây ăn trái của ĐBSCL. Số liệu thống kê đến năm 2017 cho thấy ĐBSCL chiếm 46.1\% diện tích và $64.4 \%$ sản lượng xoài của cả nước. Tổng kim ngạch xuất khẩu xoài và các sản phẩm chế biến từ xoài năm 2018 đạt 193.2 triệu USD (tăng 24\% so năm 2017), chiếm 5\% trong tổng kim ngạch xuất khẩu rau quả (Hung Phu, 2019). Nghiên cứu này được thực hiện nhằm phân tích các yếu tố có ảnh hưởng đến việc chấp nhận áp dụng tiêu chuẩn VietGAP vào sản xuất cây ăn trái của nông dân ở ĐBSCL qua trường hợp hộ trồng xoàiKết quả nghiên cứu sẽ cung cấp những luận cứ khoa học quan trọng về yếu tố ảnh hưởng đến việc áp dụng VietGAP trên cây xoài cũng như cây ăn trái cho các nhà quản lý và hoạch định chính sách ở ĐBSCL.

\section{Cơ sở lý thuyết}

\subsection{Một số thuật ngũ̃ và định nghĩa sử dụng trong VietGAP trồng trọt}

Theo tiêu chuẩn TCVN11892-1:2017, một số thuật ngữ và định nghĩa quan trọng được sử dụng như sau:

+ Thực hành nông nghiệp tốt trong trồng trọt (Good Agricultural Practices for crop 
production): Gồm những yêu cầu trong sản xuất, sơ chế sản phẩm trồng trọt để bảo đảm an toàn thực phẩm; chất lượng sản phẩm; sức khỏe và an toàn lao động đối với người sản xuất; bảo vệ môi trường và truy nguyên nguồn gốc sản phẩm;

+ Thực phẩm: Sản phẩm mà con người ăn, uống ở dạng tươi sống hoặc đã qua sơ chế, chế biến, bảo quản. Thực phẩm không bao gồm mỹ phẩm, thuốc lá và các chất sử dụng như dược phẩm;

+ Sản xuất: Gồm các hoạt động từ gieo trồng đến thu hoạch, sơ chế và đóng gói tại nơi sản xuất hoặc vận chuyển đến nơi sơ chế;

+ So chế: Bao gồm hoạt động loại bỏ những phần không sử dụng làm thực phẩm, phân loại, làm sạch, làm khô, đóng gói nhằm tạo ra thực phẩm tươi sống có thể ăn ngay hoặc tạo ra nguyên liệu thực phẩm hoặc bán thành phẩm cho khâu chế biến thực phẩm;

+ Kiểm tra nội bộ: Quá trình kiểm tra để xác định mức độ thực hiện và duy trì sự phù hợp với VietGAP trong quá trình sản xuất, sơ chế, được lập thành văn bản, do cơ sở sản xuất tổ chức thực hiện.

\subsection{Các yêu cầu cần đáp úng khi áp dụng VietGAP}

Theo tiêu chuẩn TCVN11892-1:2017, các yêu cầu cơ bản người sản xuất cần đáp ứng khi áp dụng VietGAP như sau:

+ Các tiêu chuẩn về kỹ thuật sản xuất: Tiêu chuẩn VietGAP sẽ thiết lập các yêu cầu cụ thể về kỹ thuật sản xuất cho từng khâu trong quá trình sản xuất, sơ chế sản phẩm trồng trọt, bao gồm đánh giá và lựa chọn vùng sản xuất; giống; quản lý đất và giá thể; phân bón và chất phụ gia; nước tưới cho cây trồng; hóa chất (gồm phân vô cơ và thuốc bảo vệ thực vật); thu hoạch và xử lý sau thu hoạch; quản lý và xử lý chất thải; an toàn lao động; ghi chép, lưu trữ hồ sơ, truy xuất nguồn gốc và thu hồi sản phẩm; kiểm tra nội bộ; khiếu nại và giải quyết khiếu nại;

+ An toàn thực phẩm: Nhà sản xuất phải đảm bảo các nông sản không bị nhiễm độc do chất bảo quản hay dư lượng kháng sinh từ sản xuất tới khi lưu thông sản phẩm trên thị trường. Đảm bảo thực phẩm luôn đạt chuẩn về an toàn, không làm ảnh hưởng tới sức khỏe của người tiêu dùng;

+ Môi trường làm việc: Các yếu tố về vấn đề lao động cần phải được kiểm soát để đảm bảo không lạm dụng người lao động quá mức;

+ Truy xuất nguồn gốc sản phẩm: Các sản phẩm trồng trọt từ khâu đầu vào tới khi trở thành thành phẩm được tiêu thụ cần phải đảm bảo có nguồn gốc rõ ràng và có thể truy xuất cụ thể nguồn gốc của chúng.

\subsection{Nghiên cứu trước về yếu tố ảnh hướng đến việc áp dụng GAP (VietGAP)}

Các yếu tố có liên quan đến đặc điểm nhân khẩu có xu hưởng ảnh hưởng đến việc áp dụng GAP vào sản xuất như:

Trình độ học vấn của chủ hộ có ảnh hưởng tích cực đến quyết định áp dụng GAP của người sản xuất (Bui et al., 2020); tuy nhiên trong nghiên cứu của Le và cộng sự (2016), Suwanmaneepong, Kullachai, và Fakkhong (2016) và Laosutsan, Shivakoti, và Soni (2019) cho thấy trình độ học vấn không ảnh hưởng đến việc chấp nhận áp dụng GAP.

Kinh nghiệm sản xuất của nông hộ có ảnh hưởng tích cực đến việc tham gia áp dụng GAP 
của hộ sản xuất (Suwanmaneepong et al., 2016). Nghiên cứu của Ho và cộng sự (2017) cho rằng kinh nghiệm sản xuất có ảnh hưởng nghịch chiều đến quyết định áp dụng GAP. Tuy nhiên, một số nghiên cứu lại cho thấy kinh nghiệm sản xuất không ảnh hưởng đến việc chấp nhận áp dụng GAP (Bui et al., 2020; Laosutsan et al., 2019).

Về tuổi của chủ hộ, các nghiên cứu cũng chỉ ra tuổi của chủ hộ không ảnh hưởng đến quyết định áp dụng GAP vào sản xuất của nông hộ (Laosutsan et al., 2019; Le et al., 2016; Suwanmaneepong et al., 2016).

Số lao động trong nông hộ có ảnh hưởng tích cực đến quyết định áp dụng GAP vào sản xuất của nông dân (Ho et al., 2017); tuy nhiên một số nghiên cứu lại cho thấy số lao động gia đình không ảnh hưởng đến việc chấp nhận áp dụng GAP của người sản xuất (Laosutsan et al., 2019; Suwanmaneepong et al., 2016).

Tham gia là thành viên của tổ chức nông dân có ảnh hưởng lớn đến việc áp dụng GAP vào sản xuất (Le et al., 2016); tuy nhiên kết quả nghiên cứu của Suwanmaneepong và cộng sự (2016) cho thấy việc tham gia vào tổ chức nông dân không ảnh hưởng đến việc chấp chập nhận áp dụng GAP.

Về việc tiếp cận thông tin, kết quả nghiên cứu của Le và cộng sự (2016) cho thấy nếu nông hộ có tiếp cận được các thông tin về sản xuất GAP sẽ có tác động tích cực đến việc chấp nhận áp dụng quy trình GAP vào sản xuất.

Các kết quả nghiên cứu trước cho thấy, diện tích đất canh tác là yếu tố quan trọng ảnh hưởng tích cực đến quyết định áp dụng GAP của người sản xuất (Ho et al., 2017; Laosutsan et al., 2019). Trong khi đó, kết quả nghiên cứu của Le và cộng sự (2016) chỉ ra diện tích đất sản xuất có tác động nghịch chiều đến quyết định áp dụng quy trình GAP vào sản xuất. Nghiên cứu của Bui và cộng sự (2020) và Suwanmaneepong và cộng sự (2016) cho thấy diện tích đất sản xuất không có ảnh hưởng đến việc áp dụng GAP.

Về độ tuổi của vườn cây, kết quả nghiên cứu của Ho và cộng sự (2017) cho thấy số tuổi của vườn cây có ảnh hưởng nghịch chiều đến quyết định tham gia vào sản xuất GAP của nông hộ.

\subsection{Phưong pháp tiếp cận}

Nghiên cứu về các yếu tố ảnh hưởng đến việc áp dụng VietGAP vào sản xuất của hộ trồng xoài ở ĐBSCL dựa trên quy trình nghiên cứu của Bhatacherjee (2012) được thể hiện qua Hình 1. Theo đó, suy luận diễn dịch là quá trình tìm ra kết luận về một hiện tượng hay hành vi dựa trên nền tảng lý thuyết hoặc suy luận logic từ tập hợp các tiên đề. Quá trình suy luận quy nạp đưa ra kết luận dựa trên các sự kiện thực tế và các chứng cứ đã quan sát, thu thập được.

Trong nghiên cứu này, các yếu tố ảnh hưởng đến việc áp dụng VietGAP vào sản xuất của hộ trồng xoài được chọn làm vấn đề nghiên cứu. Quá trình suy luận diễn dịch được thực hiện thông qua lược khảo tài liệu và xác định được các yếu tố ảnh hưởng đến việc chấp nhận áp dụng GAP vào sản xuất của nông hộ như tuổi và trình độ học vấn của chủ hộ, kinh nghiệm sản xuất, số lao động trong nông hộ, tham gia các tổ chức nông dân, ... Tuy nhiên, chưa có nghiên cứu để xác định các yếu tố tác động đến việc chấp nhận áp dụng VietGAP ở ĐBSCL và cụ thể là trường hợp hộ sản xuất xoài. Quá trình suy luận quy nạp được thực hiện thông qua khảo sát thực tế, so sánh, phân tích và đánh giá giữa nhóm hộ áp dụng VietGAP và hộ không áp dụng VietGAP để đưa ra kết luận và các giải pháp khuyến nghị phù hợp nhằm nâng cao khả năng chấp nhận áp dụng tiêu chuẩn VietGAP của hộ trồng xoài. Do đó, chúng tôi sử dụng song song hai quá trình diễn dịch và quy nạp để xây dựng mô hình nghiên cứu. 


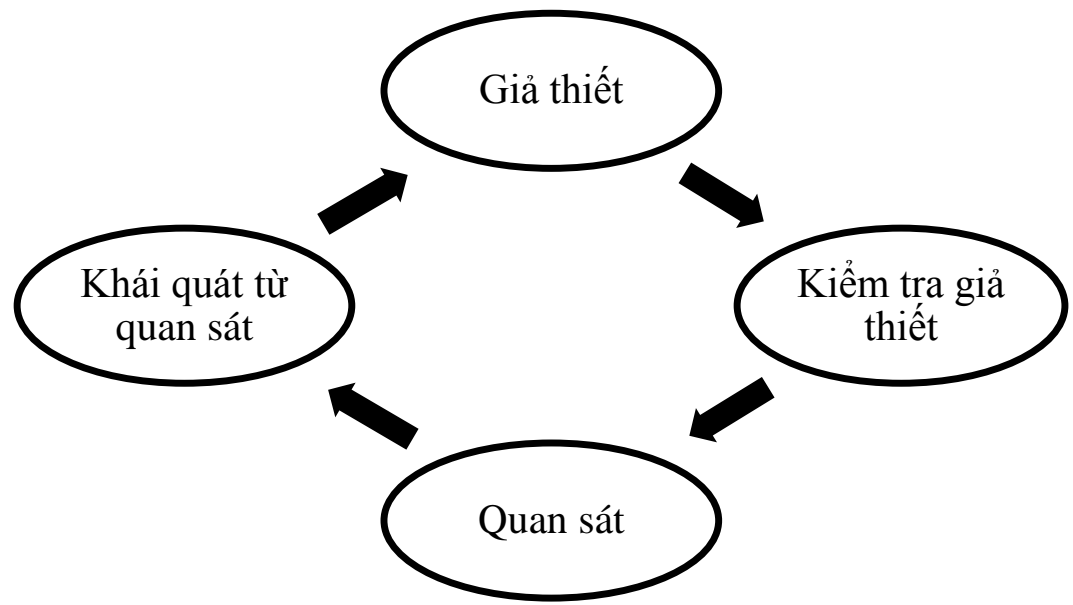

Hình 1. Quy trình nghiên cứu

\section{Phương pháp nghiên cứu}

\subsection{Mô hình nghiên cúu}

Dựa vào kết quả của các nghiên cứu trước về yếu tố ảnh hưởng đến việc áp dụng GAP vào sản xuất của hộ nông dân được thực hiện ở trong và ngoài nước cùng các quan sát thực tế tại vùng nghiên cứu, tác giả đề xuất mô hình hồi quy nhị phân như sau:

$$
\operatorname{Ln} \frac{Y(P=1)}{Y(P=0)}=B_{0}+B_{1} X_{1}+B_{2} X_{2}+\cdots+B_{8} X_{8}+B_{9} X_{9}
$$

Trong đó: Y là biến phụ thuộc (nhị phân), thể hiện việc áp dụng quy trình VietGAP vào sản xuất, được đo lường bằng hai giá trị 1 và 0 (1 là nông hộ có áp dụng VietGAP, 0 là nông hộ không áp dụng VietGAP). Các biến $X_{1}, X_{2}, X_{3}, X_{4}, X_{5}, X_{6}, X_{7}, X_{8}$ và $X_{9}$ là các biến độc lập (biến giải thích) và được diễn giải chi tiết ở Bảng 1 . Trong mô hình nghiên cứu, hai biến $\mathrm{X}_{7}$ "máy tính có kết nối internet" và $\mathrm{X}_{9}$ "số lần gặp $\mathrm{CBKN}$ " được đề xuất đưa vào mô hình.

\section{Bảng 1}

Diễn giải các biến giải thích trong mô hình hồi quy nhị phân

\begin{tabular}{|l|l|l|}
\hline \multicolumn{1}{|c|}{ Biến giải thích } & \multicolumn{1}{|c|}{ Diễn giải } & \multicolumn{1}{|c|}{ Nguồn tham khảo } \\
\hline$X_{1}$ : Tuổi của chủ hộ & Biến liên tục (tuổi) & $\begin{array}{l}\text { Laosutsan và cộng sự (2019); } \\
\text { Suwanmaneepong vàng sự (2016); Le } \\
\text { và cộng sự (2016) }\end{array}$ \\
\hline $\begin{array}{l}X_{2} \text { : Kinh nghiệm sản xuất } \\
\text { của hộ }\end{array}$ & Biến liên tục (năm) & $\begin{array}{l}\text { Bui và cộng sự (2020); Laosutsan và cộng } \\
\text { sự (2019); Ho và cộng sự (2017); } \\
\text { Suwanmaneepong và cộng sự (2016) }\end{array}$ \\
\hline $\begin{array}{l}X_{3}: \text { Trình độ học vấn của } \\
\text { chủ hộ }\end{array}$ & Biến liên tục (năm học) & $\begin{array}{l}\text { Bui và cộng sự (2020); Laosutsan và cộng } \\
\text { sự (2019); Le và cộng sự (2016); } \\
\text { Suwanmaneepong và cộng sự (2016) }\end{array}$ \\
\hline $\begin{array}{l}X_{4}: \text { Số lao động nông } \\
\text { nghiệp }\end{array}$ & Biến liên tục (người) & $\begin{array}{l}\text { Ho và cộng sự (2017); Laosutsan và cộng } \\
\text { sự (2019); Suwanmaneepong và cộng sự } \\
\text { (2016) }\end{array}$ \\
\hline $\begin{array}{l}X_{5}: \text { Tham gia tổ chức cho } \\
\text { nông dân }\end{array}$ & $\begin{array}{l}\text { Biến nhị phân, nông hộ } \\
\text { có tham gia tổ chức } \\
\text { nông dân = 1, khác = }\end{array}$ & $\begin{array}{l}\text { Le và cộng sự (2016); Suwanmaneepong } \\
\text { và cộng sự (2016) }\end{array}$ \\
\hline
\end{tabular}




\begin{tabular}{|l|l|l|}
\hline $\mathrm{X}_{6}$ : Số lần gặp CBKN & Biến liên tục (lần) & Tác giả đề xuất (dựa vào quan sát thực tế) \\
\hline $\mathrm{X}_{7}$ : Diện tích vườn xoài & Biến liên tục (ha) & $\begin{array}{l}\text { Laosutsan và cộng sự (2019); Ho và cộng } \\
\text { sự (2017); Le và cộng sự (2016); Bui và } \\
\text { cộng sự (2020); Suwanmaneepong và } \\
\text { cộng sự (2016) }\end{array}$ \\
\hline $\begin{array}{l}\mathrm{X}_{8} \text { : Máy tính có kết nối } \\
\text { internet }\end{array}$ & $\begin{array}{l}\text { Biến nhị phân, máy tính } \\
\text { có kết nối internet }=1, \\
\text { khác }=0\end{array}$ & Tác giả đề xuất (dựa vào quan sát thực tế) \\
\hline $\mathrm{X}_{9}$ : Số tuổi vườn xoài & Biến liên tục (năm) & Ho và cộng sự (2017) \\
\hline
\end{tabular}

Nguồn: Tác giả xây dựng

\subsection{Nguồn số liệu}

Chọn vùng nghiên cứu: xã An Lạc Tây, huyện Kế Sách, tỉnh Sóc Trăng và thị trấn Bảy Ngàn, huyện Châu Thành $\mathrm{A}$, tỉnh Hậu Giang đã được lựa chọn có chủ ý để thực hiện nghiên cứu. An Lạc Tây là xã có 47 nông dân trồng xoài đạt chứng nhận VietGAP với diện tích 34 ha (trong tổng sô 121 ha diện tích đất trồng xoài của xã) vào năm 2018. Theo báo cáo của Chi cục Trồng trọt và Bảo vệ Thực vật tỉnh Sóc Trăng (2020), đây là địa phương duy nhất trong tỉnh có nông dân trồng xoài đạt chứng nhận VietGAP. Tương tự, thị trấn Bảy Ngàn cũng là địa phương duy nhất của tỉnh Hậu Giang có 20 nhà vườn trồng xoài đạt chứng nhận VietGAP với diện tích 18.1 ha (trong tổng số 162 ha diện tích đất trồng xoài của thị trấn), vào năm 2015. Sóc Trăng và Hậu Giang cũng được xem là những tỉnh có tỉ lệ diện tích sản xuất theo VietGAP điển hình trong vùng. Cũng theo số liệu thống kê của Chi cục Trồng trọt và Bảo vệ Thực vật tỉnh Sóc Trăng (2020), diện tích cây ăn trái được sản xuất theo tiêu chuẩn VietGAP ở tỉnh Sóc Trăng đạt 370 ha, chiếm khoảng $1.3 \%$ diện tích cây ăn trái của tỉnh. Trong khi đó, báo cáo năm 2020 của Trung tâm Khuyến nông tỉnh Hậu Giang cho thấy diện tích sản xuất cây ăn trái theo chuẩn VietGAP tỉnh Hậu Giang chỉ đạt 303 ha, chiếm $0.76 \%$ tổng diện tích cây ăn trái.

Chọn mẫu nghiên cứu: phương pháp chọn mẫu phân tầng được áp dụng nhằm xác định hai nhóm hộ trồng xoài để khảo sát: (1) nhóm hộ áp dụng VietGAP và (2) nhóm hộ không áp dụng VietGAP. Nhóm hộ áp dụng VietGAP (đã có giấy chứng nhận) được lựa chọn từ danh sách nông dân tham gia áp dụng VietGAP; trong khi đó, nhóm hộ còn lại được lựa chọn theo phương pháp thuận tiện. Tuy nhiên, hộ không áp dụng VietGAP phải cư ngụ trên cùng địa bàn với nhóm nông hộ sản xuất theo VietGAP, điều này nhằm đảm bảo tính đồng nhất về cơ sở hạ tầng giao thông, đặc điểm văn hóa cũng như điều kiện sản xuất cho cả hai nhóm hộ. Tổng số đơn vị mẫu khảo sát là 110 hộ, gồm 49 nông hộ áp dụng VietGAP và 61 không áp dụng VietGAP.

Phương pháp phỏng vấn trực tiếp nông hộ thông qua bản câu hỏi cấu trúc được thực hiện nhằm thu thập thông tin, số liệu có liên quan đến đặc điểm kinh tế - xã hội, tuổi tác, trình độ học vấn, kinh nghiệm sản xuất, nguồn nhân lực, quy mô sản xuất và nguồn lực về vốn xã hội của nông hộ.

\section{Kết quả nghiên cứu}

\section{1. Đặc điểm kinh tế - xã hội của mẫu khảo sát}

Về đặc điểm nhân khẩu học của nông hộ, kết quả ở Bảng 2 cho thấy không có sự khác biệt ý nghĩa thống kê về tuổi và kinh nghiệm sản xuất giữa chủ hộ hộ áp dụng VietGAP và hộ không áp dụng VietGAP. Chủ hộ có áp dụng VietGAP có khuynh hướng lớn tuổi hơn chủ hộ còn lại nhưng kinh nghiệm sản xuất lại có xu hướng ít hơn. Trình độ học vấn của nông dân là một trong những yếu tố quan trọng giúp nâng cao hiệu quả ứng dụng tiến bộ khoa học kỹ thuật vào sản xuất. Kết quả khảo sát cho thấy trình độ học vấn của chủ hộ sản xuất theo VietGAP có xu hướng cao 
hơn so với hộ sản xuất theo truyền thống (khác biệt thống kê ở mức ý nghĩa $10 \%$ ). Điều này ngụ ý rằng, tuổi của chủ hộ có thể ảnh hưởng đến việc lựa chọn sản xuất theo quy chuẩn VietGAP. Về nguồn nhân lực của nông hộ, kết quả phân tích cho thấy số lao động nông nghiệp của nhóm hộ áp dụng quy chuẩn VietGAP có xu hướng ít hơn so với nhóm hộ sản xuất tự do và có sự khác thống kê ở mức ý nghĩa $1 \%$. Điều này ngụ ý rằng số lao động của nông hộ có thể ảnh hưởng đến việc quyết định áp dụng quy chuẩn VietGAP của nông hộ. Vốn xã hội của hộ áp dụng quy chuẩn VietGAP có xu hướng tốt hơn so với nhóm nông hộ sản xuất theo truyền thống như tham gia vào các tổ chức nông dân và tiếp xúc với $\mathrm{CBKN}$. Nông hộ có tham gia vào các tổ chức nông dân như hợp tác xã, tổ hợp tác, câu lạc bộ khuyến nông có thể giúp họ dễ chấp nhận áp dụng quy chuẩn VietGAP hơn. Kết quả khảo sát cho thấy có $92 \%$ hộ sản xuất theo VietGAP tham gia vào các tổ chức nông dân, trong khi đó chỉ có $2 \%$ số hộ sản xuất theo truyền thống là thành viên của tổ chức nông dân. Kết quả của việc tham gia vào các tổ chức nông dân có thể giúp cho nông hộ có nhiều cơ hội tiếp cận với $\mathrm{CBKN}$ hơn (Bảng 2 ), qua đó giúp nông dân được $\mathrm{CBKN}$ tư vấn và hướng dẫn kỹ thuật dễ dàng hơn.

Về tài nguyên sản xuất của nông hộ, kết quả khảo sát cho thấy hộ áp dụng quy chuẩn VietGAP không nhất thiết phải có diện tích đất quá lớn. Kết quả phân tích hầu như không có sự khác biệt về diện tích đất sản xuất xoài giữa hai nhóm hộ. Số tuổi vườn xoài của hộ áp dụng quy chuẩn VietGAP khá cao so với tuổi vườn xoài của hộ sản xuất theo truyền thống. Điều này có thể được lý giải rằng khi tuổi vườn xoài lớn thì nông dân dễ chấp nhận áp dụng quy chuẩn VietGAP vào sản xuất do cây đã ổn định năng suất và ít rủi ro khi áp dụng quy trình canh tác mới.

Kết quả ở Bảng 2 cho thấy nhóm hộ áp dụng quy chuẩn VietGAP có điều kiện tiếp cận thông tin từ Internet tốt hơn so với nhóm hộ còn lại. Kết quả phân tích cho thấy có $65 \%$ hộ áp dụng VietGAP có máy vi tính được kết nối với internet, trong khi đó tỷ lệ này chỉ đạt $16 \%$ ở hộ sản xuất theo truyền thống. Điều này ngụ ý rằng, khi nông dân có nhiều cơ hội tiếp cận với thông tin (thông qua Internet) có thể giúp nông hộ dễ chấp nhận áp dụng quy chuẩn VietGAP hơn.

Nhìn chung, đặc điểm kinh tế - xã hội giữa nhóm hộ áp dụng VietGAP và hộ sản xuất truyền thống có sự khác biệt cơ bản về trình độ học vấn, số lao động trong nông hộ và tham gia vào tổ chức nông dân.

\section{Bảng 2}

Đặc điểm của các biến được sử dụng trong mô hình hồi quy nhị phân

\begin{tabular}{|l|c|c|c|}
\hline \multicolumn{1}{|c|}{ Tiêu chí } & $\begin{array}{c}\text { Hộ sản xuất theo } \\
\text { VietGAP }\end{array}$ & $\begin{array}{c}\text { Hộ không áp } \\
\text { dụng VietGAP }\end{array}$ & $\begin{array}{c}\text { Khác biệt } \\
\text { trung bình }\end{array}$ \\
\hline Tuổi của chủ hộ (tuổi) & 54.53 & 53.25 & 1.285 \\
\hline Kinh nghiệm sản xuất xoài (năm) & 24.63 & 26.67 & -2.039 \\
\hline Trình độ học vấn của chủ hộ (số năm học) & 7.16 & 6.20 & $0.967^{*}$ \\
\hline Số lao động nông nghiệp (người) & 2.06 & 2.75 & $-0.693^{* *}$ \\
\hline Tham gia tổ chức nông dân (nhị phân) & 0.90 & 0.02 & $0.882^{* * *}$ \\
\hline Số lần gặp CBKN (lần/năm) & 1.69 & 0.74 & $0.956^{* * *}$ \\
\hline Diện tích xoài (ha) & 0.92 & 0.89 & 0.301 \\
\hline Máy tính có kết nối internet (nhị phân) & 0.65 & 0.16 & $0.489^{* * *}$ \\
\hline Số tuổi vườn xoài (năm) & 23.80 & 17.59 & $6.206^{* * *}$ \\
\hline
\end{tabular}

Nguồn: Tác giả phân tích 


\subsection{Phân tích yếu tố ảnh hưởng đến việc áp dụng quy chuẩn VietGAP vào sản xuất của nông họ}

Kết quả ở Bảng 3 cho thấy mức độ phù hợp của mô hình có mức ý nghĩa thống kê 1\%. Mức độ dự báo đúng của mô hình là $95.5 \%$. Kết quả kiểm định cho thấy có bốn biến độc lập tác động có ý nghĩa thống kê đến việc áp dụng VietGAP vào sản xuất của hộ trồng xoài. Các biến kinh nghiệm sản xuất của nông hộ và biến máy tính có kết nối Internet có tác động ở mức ý nghĩa thống kê $10 \%$, và biến số lần gặp $\mathrm{CBKN}$ ảnh hưởng đến việc áp dụng quy trình VietGAP ở mức ý nghĩa thống kê $5 \%$. Biến tham gia tổ chức nông dân có ảnh hưởng lớn nhất đến việc áp dụng quy trình VietGAP và có ý nghĩa thống kê $1 \%$.

Biến "kinh nghiệm sản xuất của nông hộ" (X2) có mối quan hệ nghịch chiều với biến quyết định áp dụng quy chuẩn VietGAP vào sản xuất xoài $(\mathrm{Y})$. Giá trị biến $\mathrm{X} 2$ càng tăng thì giá trị của biến $\mathrm{Y}$ càng gần 0 , với điều kiện các yếu tố khác không đổi. Điều này có thể được giải thích là do kinh nghiệm sản xuất càng nhiều thì nông hộ thường không muốn thay đổi quy trình kỹ thuật sản xuất mà mình đã quen và có kinh nghiệm, việc áp dụng quy trình sản xuất mới có thể mang lại không ít rủi ro nên có thể họ chưa sẵn sàng chấp nhận áp dụng VietGAP vào sản xuất. Kết quả nghiên cứu này tương đồng với nghiên cứu của Ho và cộng sự (2017). Tuy nhiên, nghiên cứu của Suwanmaneepong và cộng sự (2016) lại cho thấy kinh nghiệm sản xuất có ảnh hưởng tích cực đến việc tham gia áp dụng GAP của hộ sản xuất. Trong khi đó, các nghiên cứu của Bui và cộng sự (2020) và Laosutsan và cộng sự (2019) lại cho thấy kinh nghiệm sản xuất không ảnh hưởng đến việc chấp nhận áp dụng GAP.

Biến "tham gia tổ chức xã hội” (X5) có ảnh hưởng lớn nhất đến quyết định của nông hộ trong việc áp dụng quy chuẩn VietGAP vào sản xuất xoài. Biến X5 là biến nhị phân hay là biến định danh chỉ nhận hai giá trị đại diện (1: có áp dụng VietGAP, 0: không áp dụng) nên xác suất biến Y nhận giá trị 1 (có áp dụng VietGAP) rất lớn nếu biến X5 bằng 1 (nông hộ có tham gia tổ chức nông dân) với điều kiện các yếu tố khác không đổi. Điều này ngụ ý rằng, nếu nông hộ có tham gia các tổ chức nông dân thì khả năng áp dụng quy chuẩn VietGAP vào sản xuất sẽ cao hơn so với những hộ không là thành viên của các tổ chức nông dân. Kết quả này tương tự như nghiên cứu của Le và cộng sự (2016). Tuy nhiên, nghiên cứu của Suwanmaneepong và cộng sự (2016) cho thấy việc tham gia vào tổ chức nông dân không ảnh hưởng đến việc chấp chập nhận áp dụng GAP.

Biến "số lần gặp CBKN" (X6) có mối quan hệ thuận chiều với việc quyết định áp dụng quy trình VietGAP vào sản xuất của nông dân. Biến X6 là một biến liên tục, giá trị biến X6 càng tăng (số lần gặp CBKN càng nhiều) thì xác suất biến Y nhận giá trị 1 (quyết định áp dụng VietGAP) càng cao, trong điều kiện các yếu tố khác không đổi. Điều này có thể được giải thích rằng nông hộ gặp gỡ và tiếp xúc với $C B K N$ nhiều sẽ giúp tăng khả năng hiểu biết và nhận thức của họ về lợi ích của mô hình VietGAP nên họ sẵn sàng chấp nhận áp dụng.

Biến "máy tính có kết nối Internet" (X8) cũng có mối quan hệ thuận chiều đến quyết định áp dụng quy chuẩn VietGAP vào sản xuất. Biến X8 là một biến định danh, nhận 02 giá trị đại diện (1: có áp dụng VietGAP, 0 : không áp dụng) nên xác suất biến $Y$ nhận giá trị 1 càng lớn nếu biến X8 bằng 1 , trong điều kiện các yếu tố khác không đổi. Điều này có thể được giải thích, khi nông hộ được tiếp cận thêm với các thông tin từ Internet sẽ giúp tăng sự hiểu biết về tiêu chuẩn VietGAP nên dễ dàng chấp nhận áp dụng quy trình VietGAP vào sản xuất.

Tuy nhiên, các biến còn lại như "tuổi của chủ hộ", "trình độ của chủ hộ", "số lao động nông nghiệp", "diện tích trồng xoài” và "số tuổi vườn xoài" không có ảnh hưởng đến việc chấp nhận áp dụng tiêu chuẩn VietGAP của nông hộ.

Biến "tuổi của chủ hộ" có tác động cùng chiều đến việc chấp nhận áp dụng VietGAP của 
hộ trồng xoài nhưng không có ý nghĩa thống kê. Kết quả này cũng phù hợp với các kết quả nghiên cứu của Laosutsan và cộng sự (2019), Suwanmaneepong và cộng sự (2016) và Le và cộng sự (2016), tuổi không ảnh hưởng đến việc áp dụng quy chuẩn GAP của hộ.

Kết quả ở Bảng 3 cho thấy biến "trình độ học vấn của chủ hộ" có tác động nghịch chiều đến việc áp dụng VietGAP của nông hộ nhưng không có ý nghĩa thống kê. Kết quả này cũng phù hợp với nghiên cứu của Le và cộng sự (2016), Suwanmaneepong và cộng sự (2016) và Laosutsan và cộng sự (2019), trình độ học vấn không ảnh hưởng đến việc chấp nhận áp dụng GAP. Tuy nhiên, nghiên cứu của Bui và cộng sự (2020) cho thấy trình độ học vấn của chủ hộ có ảnh hưởng tích cực đến quyết định áp dụng GAP của người sản xuất.

Kết quả phân tích cũng cho thấy biến "số lao động nông nghiệp" không có ảnh hưởng đến việc chấp nhận áp dụng VietGAP (Bảng 3). Điều này cũng phù hợp với của Laosutsan và cộng sự (2019) và Suwanmaneepong và cộng sự (2016). Ngược lại, nghiên cứu của Ho và cộng sự (2017) cho thấy số lao động trong nông hộ có ảnh hưởng tích cực đến quyết định áp dụng VietGAP của nông dân.

Biến "diện tích trồng xoài" không có tác động đến việc chấp nhận áp dụng tiêu chuẩn VietGAP của nông hộ (Bảng 3 ). Kết quả này phù hợp với nghiên cứu của tác giả Bui và cộng sự (2020) và Suwanmaneepong và cộng sự (2016). Tuy nhiên, kết quả nghiên cứu của Laosutsan và cộng sự (2019) và Ho và cộng sự (2017) cho thấy, diện tích đất canh tác ảnh có hưởng tích cực việc chấp nhận áp dụng GAP của nông hộ. Ngược lại, kết quả nghiên cứu của Le và cộng sự (2016) lại cho thấy diện tích đất sản xuất có tác ảnh hưởng nghịch chiều đến việc chấp nhận dụng tiêu chuẩn GAP của hộ sản xuất.

Biến "số tuổi vườn xoài" cũng không có ảnh hưởng đến việc chấp nhận áp dụng tiêu chuẩn VietGAP của hộ trồng xoài. Tuy nhiên, trong nghiên cứu của Ho và cộng sự (2017) cho thấy độ tuổi của cây trồng có ảnh tác động nghịch chiều đến việc chấp nhận áp dụng VietGAP của nông hộ.

\section{Bảng 3}

Kết quả phân tích mô hình hồi quy logit

\begin{tabular}{|l|c|c|c|c|c|}
\hline \multicolumn{1}{|c|}{ Tiêu chí } & B & S.E. & Wald & Sig. & $\mathbf{E x p ( B ) ~}$ \\
\hline $\mathrm{X}_{1}$ : Tuổi của chủ hộ & 0.032 & 0.081 & 0.159 & 0.690 & 1.033 \\
\hline $\mathrm{X}_{2}$ : Kinh nghiệm sản xuất của hộ & -0.152 & 0.089 & 2.885 & $0.089^{*}$ & 0.859 \\
\hline $\mathrm{X}_{3}$ : Trình độ học vấn của chủ hộ & -0.047 & 0.213 & 0.049 & 0.824 & 0.954 \\
\hline $\mathrm{X}_{4}$ : Số lao động nông nghiệp & 0.493 & 0.484 & 1.036 & 0.309 & 1.637 \\
\hline $\mathrm{X}_{5}$ : Tham gia tổ chức cho nông dân & 8.033 & 2.384 & 11.356 & $0.001^{* * *}$ & 3.080 \\
\hline $\mathrm{X}_{6}$ : Số lần gặp CBKN & 1.003 & 0.463 & 4.697 & $0.030^{* *}$ & 2.726 \\
\hline $\mathrm{X}_{7}$ : Diện tích trồng xoài & 0.000 & 0.000 & 0.187 & 0.665 & 1.000 \\
\hline $\mathrm{X}_{8}$ : Máy tính có kết nối Internet & 2.303 & 1.262 & 3.330 & $0.068^{*}$ & 10.008 \\
\hline $\mathrm{X}_{9}$ : Số tuối vườn xoài & -0.037 & 0.070 & 0.278 & 0.598 & 0.964 \\
\hline Hằng số & -3.673 & 5.013 & 0.537 & 0.464 & 0.025 \\
\hline Hệ số sig. của mô hình $=0.000$ & & & & & \\
\hline Hệ số hiệu chỉnh $\mathrm{R}^{2}=0.88$ & & & & & \\
\hline Xác suất dự đoán đúng $=95.5 \%$ & & & & & \\
\hline
\end{tabular}

Ghi chú: ** và *** khác biệt ở mức ý nghĩa lần lượt là $5 \%$ và $10 \%$

Nguồn: Tác giả phân tích 


\section{Kết luận}

\subsection{Kết luận}

Kết quả nghiên cứu cho thấy có sự khác biệt về một số đặc điểm kinh tế - xã hội giữa nhóm hộ sản xuất xoài áp dụng quy trình VietGAP và nhóm hộ sản xuất tự do về trình độ học vấn của chủ hộ, số lao động nông nghiệp và nguồn lực về vốn xã hội của nông hộ.

Nông hộ tham gia vào các tổ chức nông dân, tiếp cận với thông tin sản xuất từ Internet và tiếp xúc nhiều với cán bộ khuyến nông ở địa phương có tác động tích cực đến việc chấp nhận áp dụng quy trình VietGAP vào sản xuất xoài. Nghiên cứu cũng chỉ ra thực tế đáng quan tâm là số năm kinh nghiệm sản xuất của nông hộ càng tăng thì họ ít có xu hướng áp dụng quy trình VietGAP vào sản xuất. Điều này có thể do nông hộ không muốn đột ngột thay đổi quy trình kỹ thuật đã áp dụng ổn định qua nhiều năm canh tác. Điểm nổi bật của nghiên cứu là xác định được số lần tiếp cận $\mathrm{CBKN}$ của nông dân và nông hộ có trang bị máy vi tính kết nối internet ảnh hưởng tích cực đến việc chấp nhận áp dụng VietGAP.

Nghiên cứu này chỉ tập trung phân tích các yếu tố định lượng có liên quan đến đặc điểm về kinh tế - xã hội của hộ ảnh hưởng đến quyết định áp dụng quy trình VietGAP vào sản xuất xoài. Nghiên cứu chưa phân tích và đánh giá các yếu tố định tính như sự kỳ vọng giá bán sản phẩm VietGAP, kỳ vọng về lợi nhuận, động cơ áp dụng VietGAP, tập quán, thói quen sản xuất của nông dân chưa được phân tích trong nghiên cứu.

\subsection{Khuyến nghị}

Tăng cường tuyên truyền cho nông dân về lợi ích của việc áp dụng quy trình VietGAP vào sản xuất, giúp nâng cao nhận thức cho nông dân về sản xuất theo hướng an toàn vệ sinh thực phẩm, góp phần bảo vệ sức khỏe cho chính người sản xuất và người tiêu dùng. Cần chú trọng phổ biến thông tin về các mô hình áp dụng VietGAP qua internet hay truyền hình.

Vai trò của $\mathrm{CBKN}$ ở địa phương cần được tăng cường và nâng cao hơn nữa trong hoạt động tập huấn, chuyển giao các tiến bộ khoa học kỹ thuật hay quy trình kỹ thuật mới cho nông dân. Đặc biệt, CBKN cần định kỳ gặp gỡ, trao đổi và tư vấn kịp thời cho nông dân những vấn đề trong sản xuất theo tiêu chuẩn VietGAP.

Nông dân cần mạnh dạn tham gia vào các tổ chức sản xuất ở địa phương như tổ hợp tác hay hợp tác xã. Các hình thức này giúp nông hộ gia tăng cơ hội tiếp cận và áp dụng những quy trình tiến bộ khoa học kỹ thuật mới vào sản xuất như VietGAP. Thêm vào đó, tham gia vào hợp tác xã còn giúp nông dân thuận lợi hơn trong liên kết tiêu thụ sản phẩm với các doanh nghiệp, đặc biệt là các sản phẩm đạt chứng nhận VietGAP.

\section{LỜI CÁM ƠN}

Nghiên cứu này được thực hiện là một phần của kết quả đề tài nghiên cứu khoa học cấp Trường "Phân tích các yếu tố ảnh hưởng đến việc chấp nhận áp dụng mô hình thực hành nông nghiệp tốt (GAP) vào sản xuất cây ăn trái (xoài) của nông dân ở ĐBSCL"; Mã số T2020-78. Nhóm tác giả xin chân thành cảm ơn trường Đại học Cần Thơ đã tài trợ toàn bộ kinh phí cho nghiên cứu này.

\section{Tài liệu tham khảo}

Bhatacherjee, A. (2012). Social science research: Principle, methods, and practices. Tampa, Florida: University of South Florida. 
Bộ công thương. (2020). Báo cáo xuất nhập khẩu Việt Nam năm 2019 [Vietnam inport - export report 2019]. Hanoi, Vietnam: NXB Công Thường.

Bộ Khoa học và Công nghệ. (2017). TCVN 11892-1:2017 - Thưc hành nông nghiệp tốt (VietGAP) - phần 1: Trồng trọt [TCVN 11892-1:2017 - Good agricultural practices (VietGAP) - Part 1: Crop production]. Retrieved October 10, 2020, from https://vanbanphapluat.co/tcvn11892-1-2017-thuc-hanh-nong-nghiep-tot-vietgap-phan-1-trong-trot

Bộ Nông nghiệp và Phát triển Nông thôn. (2008). Quyết định số 379/QĐ-BNN-KHCN ngày 28 tháng 01 năm 2008 về Quyết định ban hành quy trình thục hành sản xuất nông nghiệp tốt cho rau, quả tuooi an toàn [Decision No. 379/QD-BNN-KHCN dated January 28, 2008 about Good agricultural practices for safe fruit and vegetable production]. Retrieved October 10, 2020, from https://vanbanphapluat.co/quyet-dinh-379-qd-bnn-khcn-quy-trinh-thuc-hanhsan-xuat-nong-nghiep-tot-cho-rau-qua-tuoi-an-toan

Bui, N. X., Nguyen, T. N., Lam, T. T. M., Dang, P. M., Mai, Q. D., \& Le, N. (2020). Các yếu tố ảnh hưởng đến việc áp dụng VietGAP trong sản xuất chè búp tươi tại tỉnh Lâm Đồng [Determinants of the adoption of vietgap on tea production in Lam Dong province]. Tap Chí Nông nghiệp và PTNT, 387(2), 125-131.

Chi cục Trồng trọt và Bảo vệ Thực vật tỉnh Sóc Trăng. (2020). Báo cáo về áp dụng VietGAP trên nông, lâm, thủy sản trên địa bàn tỉnh Sóc Trăng [Report on VietGAP application to agriculture, forestry and fishery in Soc Trang province]. Retrieved December 15, 2020, from https://sonnptnt.soctrang.gov.vn/Default.aspx?sname=snnptnt\&sid=1282\&pageid= 30590

Duong, T. N., \& Nguyen, P. V. (2014). Đánh giá hiệu quả tài chính của hai mô hình sản xuất xoài cát ở tỉnh Đồng Tháp [Financial performance assessment of two mango production models in Dong Thap]. Tạp chí Khoa học Trương Đại học Cần Tho, 33(D), 1-10.

Ho, B. V., Nanseki, T., \& Chomei, Y. (2017). Factors influencing tea farmers' decision to adopt Vietnamese good agricultural practices in Northern Vietnam. Journal of Agricultural Economics and Development, 6(2), 12-20.

Hung Phu (2019). Xuất khẩu xoài tăng nhanh [Rapid increase in mango export]. Retrieved December 15, 2020, from https://nongnghiep.vn/xuat-khau-xoai-tang-nhanh-d238596.html

Laosutsan, P., Shivakoti, G. P., \& Soni, P. (2019). Factors influencing the adoption of good agricultural practices and export decision of Thailand's vegetable farmers. International Journal of the Commons, 13(2), 867-880.

Le, L. T. T., Pabuayon, I., Catelo, S., \& Sumalde, Z. (2016). Adoption of good agricultural practice (Vietgap) in the lychee industry in Vietnam. Asian Journal of Agricultural Extension, Economics \& Sociology, 8(2), 1-12.

Nguyen, C. D., Le, D. V., Tran, K. H., \& Vo, G. T. (2013). Đánh giá hiệu quả kinh tế và các lợi ích xã hội của mô hình canh tác bắp rau theo tiêu chuẩn GLOBALGAP tại Chợ Mới, An Giang [Assessment on economic return and social benefits of baby-corn farming models with GlobalGAP standard in Cho Moi, An Giang]. Tạp chí Khoa hoc Truoòng ĐH Cần Tho, 25(D), 37-44.

Pham, D. T., Pham, H. V., \& Nguyen, H. V. (2020). Phát triển sản xuất vải thiều theo tiêu chuẩn GAP tại tỉnh Bắc Giang [Development of lychee production following GAP standards in Bac Giang province]. Tạp chí Khoa học Nông nghiệp Việt Nam, 17(9), 754-763. 
Suwanmaneepong, S., Kullachai, P., \& Fakkhong, S. (2016). An investigation of factors influencing the implementation of gap among fruit farmers in Rayong province, Thailand. International Journal of Agricultural Technology, 12(7/2), 1745-1757.

Thai Nguyen (2015). Khi nông dân chua muốn sản xuất theo VietGAP [Why are farmers not willing to adopt VietGAP standards]. Retrieved December 15, 2020, from https://bnews.vn/khi-nong-dan-chua-muon-san-xuat-theo-viet-gap/350.html

Tran, H. M., Le, D. C., \& Dang, T. T. B. (2020). Đánh giá tác động của việc chuẩn hóa sản phẩm trong sản xuất lúa theo VietGAP của hợp tác xã Khiết Tâm, huyện Vĩnh Thạnh, thành phố Cần Thơ [Assessing the impacts of vietgap standardized rice product package in Khiet Tam cooperative in Vinh Thanh district, Can Tho city]. Tạp chí Khoa học Nông nghiẹp Việt Nam, 18(11), 1018-1025.

Tran, N. Q., Nguyen, T. T. H., \& Nguyen, H. T. T. (2016). Phân tích nguyên nhân nông dân từ bỏ sản xuất vú sữa Lò Rèn theo tiêu chuẩn Global GAP tại huyện Châu Thành, tỉnh Tiền Giang [Causes of farmers who abandon star-apple "Lo Ren" production with GlobalGAP standard in Chau Thanh district, Tien Giang province ]. Tạp chí Khoa học Nông nghiệp Việt Nam, 14(9), 1457-1465.

Trung tâm Khuyến nông tỉnh Hậu Giang. (2020). Báo cáo về tình hình thực hiện VietGAP trên địa bàn tỉnh Hậu Giang [Report on VietGAP models applied in Hau Giang province]. Retrieved December 15, 2020, from http://www.khuyennonghaugiang.com.vn/Default.aspx?tabid= $1456 \&$ ndid $=3180$

Vo, N. T. N. (2014). Phân tích thực trạng sản xuất chôm chôm theo tiêu chuẩn Global GAP tại tỉnh Bến Tre [Analyzing the real situation of rambutan production with Global GAP standard in Ben Tre provinc]. Tạp chí Khoa hoc Trường ĐH Cần Tho, 32(D), 69-75. 